\title{
Helisaeus Röslin y la libertad de religión 1
}

\section{Helisaeus Röslin and freedom of religion}

\author{
Miguel A. GRANADA \\ Universidad de Barcelona
}

Recibido: 17-01-2014

Aceptado: 07-04-2014

Para Carlos Gilly, que lo ha hecho posible

\section{Resumen}

En las historias generales de la tolerancia religiosa no figura Helisaeus Röslin. Sin embargo Carlos Gilly ha mostrado en diferentes trabajos que el médico suabo-alsaciano sostuvo a lo largo de su obra de modo incansable la necesidad de la libertad religiosa y de conciencia como un postulado religioso y como un factor de progreso económico y paz social. El presente trabajo pretende analizar en profundidad la teorización rösliniana de la libertad de religión poniéndola en relación con su concepción de la historia, con su obra de cronología y con su interpretación de las novedades celestes contemporáneas, en particular la nova de 1604 y el descubrimiento galileano de los planetas mediceos en 1610, tal como se refleja en dos de las últimas obras de Röslin: Mitternächtige Schiffarth (1611) y la Tabella des Welt Spiegels (1612).

Palabras clave: cronología, escatología, final de la historia, libertad de conciencia, libertad de religión, novedades celestes, planetas mediceos, proporciones numéricas en historia, reforma del calendario, segunda venida de Cristo, Tabella des Welt Spiegels.

\begin{abstract}
Helisaeus Röslin does not figure significantly in historical surveys of religious tolerance. Nevertheless, Carlos Gilly has shown in several works that the Swabian-Alsatian physician tirelessly defended throughout his life the need to uphold the freedom of religion and of conscience, both as a religious postulate and as a factor for economic progress and social peace. This article focuses on Röslin's concept of religious freedom in relation to his

\footnotetext{
1 Trabajo efectuado en el marco del proyecto de investigación FFI2009-07156 «Cosmología, teología y antropología en la primera fase de la Revolución Científica (1543-1633)», financiado por el Gobierno Español (Ministerio de Ciencia e Innovación).
} 
concept of history, his work on chronology and his interpretation of the celestial novelties of the period, particularly the nova of 1604 and Galileo's discovery of the Medicean planets in 1610, just as they appear in two of Röslin's later works: Mitternächtige Schiffarth (1611) and the Tabella des Welt Spiegels (1612).

Keywords: Chronology, eschatology, end of history, freedom of conscience, freedom of religion, celestial novelties, Medicean planets, numerical proportions in history, reform of the calendar, second coming of Christ, Tabella des Welt Spiegels.

Helisaeus Röslin (1545-1616) no es una figura comparable, por su dimensión en la historia del pensamiento, a otros contemporáneos, compatriotas e incluso amigos suyos, como Johannes Kepler o también Michael Maestlin, el maestro de Kepler en Tubinga y el más importante copernicano alemán de la generación intermedia entre Copérnico y Kepler, además de decisivo colaborador de éste último en su primer libro (Mysterium cosmographicum, Tubinga 1596). Aunque se trate en su caso de una figura de segunda o hasta tercera categoría, sin embargo Röslin (médico de profesión, de orientación médica fuertemente marcada por el paracelsismo y los intereses alquímicos, y en religión adepto de una corriente de la llamada "reforma radical" que se remitía a Caspar von Schwenckfeld) representa, en la transición del siglo XVI al XVII, una 'forma mentis' e inquietudes intelectuales y espirituales de un amplio sector de la inteligencia alemana protestante que, al margen de las tres grandes confesiones (católicos, luteranos, calvinistas) y de la confesionalización en curso, desarrolló una concepción en la que los motivos filosóficos (cosmología y astronomía, filosofía natural, alquimia y medicina) se unían a unas expectativas religiosas de marcado tono escatológico, en la convicción del próximo fin de la historia y de la cercana segunda venida de Cristo. Todo ello se ponía de manifiesto en una breve obra que Röslin publicó en 1597, titulada De opere Dei creationis y dedicada al arzobispo de Colonia y elector imperial Ernst von Bayern. En esta obra, además de proponer una nueva versión del sistema cosmológico geoheliocéntrico independiente de las propuestas de Tycho Brahe y de Nicholas Raymarus Ursus, se presentaba en forma de tesis un sistema global que podríamos denominar teocosmo-antroposófico donde la correspondencia macro y microcosmos ocupaba un lugar preferente, tal como se puede reconocer en la figura del Signaculum Mundi Pythagoricum que aparecía entre el frontispicio y la dedicatoria al elector de Colonia. ${ }^{2}$ Por ello, antes de poner de manifiesto otras razones en el curso de nuestra exposición, podemos comprender que Carlos Gilly haya introducido a Röslin en su catálogo de publicaciones y documentos relativos a los manifiestos rosacruces como uno de los antecedentes intelectuales y espirituales de la Fama y la Confessio. ${ }^{3}$

\footnotetext{
2 Véase De opere Dei creationis seu de mundo Hypotheses, Fráncfort del Meno, 1597, reedición anastática de Miguel A. Granada, en la colección Aurifodina Philosophica, Lecce, Conte Editore, 2000. Sobre la propuesta cosmológica de Röslin y su relación con Brahe y Ursus remitimos a Miguel A. Granada, El debate cosmológico en 1588: Bruno, Brahe, Rothmann, Ursus, Röslin, Nápoles, Bibliopolis, 1996 e Idem, Sfere solide e cielo fluido. Momenti del dibattito cosmologico nella seconda metà del Cinquecento, Milán, Guerini e Associati, 2002.

3 Véase Carlos Gilly, Cimelia Rhodostaurotica. Die Rosenkreuzer im Spiegel der zwischen 1610 und 1660 entstandenen Handschriften und Drucke, Ámsterdam, In de Pelikaan, 1995, p. 12.
} 
La obra por la que Gilly introducía a Röslin en la génesis de los manifiestos rosacruces era el extenso tratado manuscrito titulado Speculum et harmonia mundi, Das ist Wellt Spiegel Erster Theil, terminado en 1579. Este manuscrito había circulado ampliamente y además había sido impreso (sin conocimiento ni autorización de Röslin) en 1604. Pero en su comentario Gilly indicaba ya que «en casi todos sus escritos» Röslin se distanciaba de las confesiones establecidas, se oponía «a la coacción religiosa por parte de la autoridad política» y abogaba por la libertad religiosa y de conciencia («Libertas Religionis, Freyheit des Gewissens»). 4

En efecto, los elementos que yo he indicado al comienzo como constitutivos de la 'forma mentis' de Röslin se unían a la firme convicción y defensa de la libertad religiosa y de conciencia. En suma, Röslin era un firme partidario y defensor de la tolerancia religiosa y merece ocupar un lugar destacado en la historia de esta idea. Ahora bien, por lo general este lugar no le ha sido reconocido y así su nombre no figura en las historias de la tolerancia religiosa, como por ejemplo el librito de Henry Kamen traducido al español con el título de Nacimiento y desarrollo de la tolerancia en la Europa moderna. ${ }^{5}$ Pero tampoco lo menciona un estudioso tan sensible a este motivo como Roland H. Bainton, ${ }^{6}$ ni más recientemente aparece en la valiosa antología editada por Massimo Firpo. ${ }^{7}$ Es más, nunca es mencionado Röslin en la que todavía es hoy la historia más completa de la cuestión, la meritoria y todavía valiosísima obra de Joseph Lecler: Histoire de la tolérance au siècle de la Réforme. ${ }^{8}$

Carlos Gilly en cambio ha insistido siempre en ello en las referencias que ha hecho a Röslin en el curso de sus trabajos. Mencionaré únicamente, por su conexión con autores españoles, el importante artículo «Sebastiano Castellione, l'idea di tolleranza e l'opposizione alla politica di Filippo II». Allí, después de presentar las ideas de Castellion sobre la libertad de conciencia y tolerancia y de mostrar el uso que Antonio del Corro hizo del Conseil à la France désolée de Castellion en su Lettre envoyée a la Maiesté du Roy des Espaignes etc. Nostre Sire, impresa en $1567,{ }^{9}$ Gilly concluía su artículo con el siguiente párrafo:

Questa [necesidad de tolerancia y relación entre tolerancia y desarrollo y prosperidad económicas] era comunque l'opinione di Helisaeus Röslin, medico ed astrologo originario della Svevia e attivo in Alsazia, che, a proposito dei Paesi Bassi, scrisse nel 1611: «il re di Spagna è la più grande potenza del mondo, $[\ldots]$ non vuole più tollerare il pubblico esercizio della religione nei suoi territori, ragion per cui è venuto in perdita dei Paesi Bassi [...]. Le Provincie Unite dei Paessi Bassi [al contrario hanno] le quattro religioni con i loro pubblici esercizii [...] Dio ha benedetto questa libertà di religione come ha benedetto il loro reggimento, e ora esse, per forza e potere, sono simili ai monarchi, re e grande potenze, e la loro potenza navale le fa sentire superiori a tutti

\footnotetext{
4 Ibidem, p. 16.

5 Henry Kamen, Nacimiento y desarrollo de la tolerancia en la Europa moderna, Madrid, Alianza, 1987.

6 Roland H. Bainton, The Travail of Religious Liberty, Philadelphia, The Westminster Press, 1951.

${ }^{7}$ Massimo Firpo, Il problema della tolleranza religiosa nell'età moderna, Milán, Loescher, 1978.

8 Joseph Lecler, Histoire de la tolérance au siècle de la Réforme, París, Éditions Montaigne/Desclée de Brouwer, 1955 (reimpresión, París, Albin Michel, 1994).

${ }_{9}^{9}$ Carlos Gilly, «Sebastiano Castellione, 1'idea di tolleranza e l'opposizione alla politica di Filippo II», Rivista storica italiana, cx, 1998, pp. 144-165 (156-158).
} 
i potentati del mondo, tanto che il re di Spagna, prima unico Dominus alti Maris, deve ora confrontarsi con loro, dividendo con loro il suo potere». Sull'esempio dei Paesi Bassi Röslin mostrava anche come l'incondizionata libertà di tutte le confessioni - «papista, luterana, calvinista o anabattista»-fosse conditio sine qua non per ridare all'Impero Romano-Germanico pace religiosa, peso politico e benessere economico. Nel suo Prodromus dissertationum chronologicarum dedicato a Mattia I, Röslin cercò di proporre «in due parole» al neoeletto imperatore la soluzione che «paese e popolo» e «condizione dei tempi» urgentemente richiedevano: «Solches kan ebenmässig mit zweien Wörtern kurtz ausgesprochen werden, welche da seynd: Libertas Religionis, Freyheit der Religion oder Freyheit des Glaubens».10

Nuestro objetivo en las páginas que siguen es presentar con algo más de detalle la concepción de Röslin, atendiendo al conjunto de su obra publicada y manuscrita, y conectar dicha concepción de la libertad religiosa con algunas de sus elaboraciones conceptuales más generales, donde la idea de la tolerancia se une a la reflexión cosmológica por la vía de la interpretación del significado de las novedades celestes contemporáneas (novas de 1572, 1600 y 1604; planetas mediceos o satélites de Júpiter descubiertos por Galileo en 1610).

\section{La libertad de religión en los escritos de Röslin (1578-1609)}

Röslin publicó su primera obra en 1578. Se trata de la Theoria nova coelestium $\mu \varepsilon \tau \varepsilon \omega \rho \omega v^{11}$, obra que tuvo bastante impacto y en la que Röslin ofrecía una interpretación de las recientes novedades celestes (nova de 1572 y cometa de 1577) tanto en el plano cosmológico (donde a decir verdad adoptaba básicamente las posiciones de Cornelius Gemma y Thaddaeus Hagecius) como especialmente en lo referente a la interpretación de su significado. Para Röslin dichos fenómenos "extraordinarios" causados por la omnipotencia divina eran señales del cercano advenimiento del tiempo escatológico, del cumplimiento de las profecías bíblicas del fin. Enlazando con la interpretación del visionario francés Guillaume Postel, Röslin anunciaba el advenimiento próximo de Cristo, una venida "intra nos", espiritual, antes de la segunda venida en gloria para juzgar el mundo. Sin embargo, no hacía en ningún momento referencia a la cuestión que aquí nos ocupa, es decir, a la libertad de religión y conciencia.

Ésta se hizo presente, sin embargo, en dos trabajos redactados en 1583: uno manuscrito (el pronóstico astrológico, redactado en marzo de 1583, sobre el futuro de Gebhard von Truchsess, arzobispo de Colonia y elector imperial desde 1577); el otro impreso en enero de ese mismo año bajo el pseudónimo de Lambertus Floridus Plieningerus como vigorosa respuesta crítica a la reforma del calendario promulgada unilateralmente por el papa Gregorio XIII en 1582. En el pronóstico astrológico - favorable a Gebhard von Truchsess, a pesar de que sería depuesto por el capítulo catedralicio en mayo de 1583 después de que el Papa lo excomulgara en abril por su conversión al protestantismo, su matrimonio y su deseo de

10 Ibidem, p. 165. Gilly ha hecho consideraciones similares en uno de sus artículos más importantes. Véase C. Gilly, «'Theophrastia Sancta'. Der Paracelsismus als Religion in Streit mit den offiziellen Kirchen», en J. Telle, ed., Analecta Paracelsica. Studien zum Nachleben Theophrast von Hohenheims im deutschen Kulturgebiet der frühen Neuzeit, Stuttgart, Franz Steiner, 1994, pp. 425-488 (443-445).

${ }^{11}$ H. Röslin, Theoria nova coelestium $\mu \varepsilon \tau \varepsilon \omega \rho \omega v$, Estrasburgo, B. Jobin, 1578. 
secularizar el territorio garantizando la libertad de religión a sus habitantes - Röslin defiende esa política y asegura astrológicamente el feliz resultado de la osada iniciativa de Truchsess, aunque la "guerra de Colonia" iniciada inmediatamente y que duraría hasta 1588 terminó con victoria católica. Me limitaré únicamente a señalar que Röslin apoya su juicio, independientemente de su elaboración de todas las circunstancias astrológicas, en la constatación de que (en consonancia con la renovación que viene impuesta por la cronología de la historia y el tiempo escatológico que comienza precisamente en 1583) «ha llegado ya el tiempo en que la libertad de religión debe ser permitida». De lo contrario, a Alemania le espera el mismo futuro de guerra civil sufrido en las décadas precedentes y todavía imperante en Francia y los Países Bajos. ${ }^{12}$

Pero más importante es el escrito contra la reforma del calendario, que (como hemos dicho) Röslin publicó bajo pseudónimo en enero de 1583 y que iba a ser reimpreso en 1584 por su amigo Michael Maestlin en el marco de su propia batalla contra el calendario gregoriano. ${ }^{13}$ En este durísimo escrito Röslin se pronuncia (en lo que fue una respuesta político-

12 Hemos consultado la copia en la Württembergische Landesbibliothek Stuttgart, Cod. hist. $2^{\circ}$ fol. 549, 12, fol. 341-355. Para la indicación de otra copia y un estudio del texto véase Paul Diesner, «Das astrologische Prognostikation des Doktor Helisäus Röslin in Hagenau, betreffend den Kölner Kurfürst Gebhard von Truchsess abgefasst im März 1583», Zeitschrift für die Geschichte des Oberrheins, 93, 1941, pp. 78-107. Cf. p. 348 y Diesner p. 88: «Dan jetzt die Zeit ist, das die freyheit der religion muss sein und auch zugelassen mus werden, es müste eher himel und erden zerbrechen und zusammenfallen, und freilich bedunckt mich, es krache schon und wolle brechen, wie es im Niderlandt nun viel Jahr hero gekracht und gebrochen und noch lenger je mehr brechen und nimmermehr zu Frieden kommen wird, man gestatte dann die freiheit der religion. Also haben wir uns daraus zu spieglen, das dergleichen in Teutschland auch angehen wird, so und in dem man wehrenn will und die stifft erhaltenn, das sie nur dadurch desto mehr zerrissen und verderbet werden. In summa, so man die religion nicht freilassen wird, muss solcher Krieg und unruhe endtstehen, welcher innerhalb 20 Jahren nicht gestillt wirdt mögen werden».

13 Kurtz Bedencken Von der Emendation dess Jahrs/ durch Bapst Gregorium der XIII. fürgenommen/ und von seinem Kalender/ nach ihm Kalendarium Gregorianum perpetuum intituliert. Ob solcher den Protestierenden Ständen anzunemen seye/ oder nicht/Mit angehenckten Prognostico/ in was Zeiten wir seyen/auß dem Propheten Daniele/ Zacharia/ und Apocalypsi Johannis Hergeführt/ und was wir zu gewarten haben. Gestellt Durch Lambertum Floridum Plieningerum, im Jahr 1583. im Monat Januario/ zur Warnung und Auffmunderung der Christenheit/ sonderlich Deutscher Nation, Heidelberg, Johan Spies, 1584; el escrito de Röslin en pp. 113-162. Röslin se sirvió repetidamente del pseudónimo Lambertus Floridus Plieningerus para la redacción de un número considerable de escritos de naturaleza teológico-religiosa y orientación espiritualista, paracelsiana y schwenckfeldiana, que permanecieron inéditos. El Kurtz Bedencken es un extenso tratado de cien páginas (merecedor de un amplio estudio monográfico que lamentablemente no le ha sido concedido hasta ahora) y efectivamente pasa revista a la historia de la Iglesia para mostrar que «el Papa Romano es el gran Anticristo» (edición de 1584, p. 114 r) y que el reino del Anticristo no es un último imperio antes de la segunda venida de Cristo y tras la ruina del imperio romano, sino que éste, en su versión germánica, es el último imperio y el Anticristo una fuerza corruptora de la religión cristiana (presente sobre todo en el Papado y activa en su última fase) y que el momento histórico contemporáneo es la antesala del final, las vísperas de la segunda venida de Cristo. Sobre la reforma gregoriana del calendario y la oposición en los medios protestantes alemanes véase G. V. Coyne-M. A. Hoskin-O. Pedersen, Gregorian Reform of the Calendar, Ciudad del Vaticano, Pontificia Academia Scientiarum, Specola Vaticana, 
religiosa muy frecuente en Alemania) contra la reforma gregoriana del viejo calendario juliano, considerada por él como un intento último y desesperado por parte del Anticristo romano por recuperar en los momentos finales de la historia el poder político y la tiranía sobre las conciencias que había perdido en gran parte a lo largo del siglo XVI como consecuencia de la Reforma religiosa iniciada por Lutero. Röslin inicia su escrito (el Prólogo al lector) afirmando que tres cosas de su libro llamarán poderosamente la atención del lector: la primera que el papa de Roma sea llamado «el gran Anticristo», la tercera la atención que se concede al cálculo cronológico en su relación con la historia universal y la segunda «que yo abogo por y quiero mantener la libertad de conciencia». ${ }^{14}$ La reforma del calendario es, pues, un acto de imposición violenta y tiránica por parte de la potencia diabólica que ocupa la sede romana desde hace ya varios siglos y ha sojuzgado los espíritus y las conciencias. La oposición y el rechazo de dicha reforma por parte de los estados protestantes alemanes es, por tanto, un acto de afirmación de la libertad cristiana. La defensa de la necesidad de establecer la libertad de conciencia como parte fundamental del escrito no es otra cosa, pues, que la constatación de lo que está en juego en última instancia en la batalla del calendario: la esencia del cristianismo como libertad espiritual y de conciencia. No es de extrañar, por tanto, que en el desarrollo de este tema en el prólogo Röslin recurra a una argumentación de tono sencillamente luterano, que evoca sin nombrarlo explícitamente la argumentación del reformador en el escrito programático de 1520 La libertad cristiana, así como la doctrina de los dos reinos (de Cristo o del espíritu y del mundo) establecida en el escrito De la autoridad secular de 1523.15 La libertad consustancial al cristianismo no es, dice Röslin, una libertad de la carne y no comporta una desobediencia a la autoridad, sino una «libertad espiritual de la conciencia» concedida a todos los creyentes por Cristo con su sacrificio redentor. ${ }^{16}$ Negar la libertad de conciencia es, por consiguiente, actuar contra la voluntad de Dios

1983; F. Stieve, «Der Kalenderstreit des sechzehnten Jahrhunderts in Deutschland», en Abhandlungen der Bayerischen Akademie der Wissenschaften, III Cl., XV Band, III Abteilung, Munich 1860 y más recientemente Jürgen Hamel, «Die Rolle Michael Mästlins in der Polemik um die Kalenderreform von Papst Gregor XIII», en Gerhardt Betsch-Jürgen Hamel, eds., Zwischen Copernicus und Kepler -Michael Maestlinus Mathematicus Goeppingensis 1550-1631, Acta Historica Astronomiae vol. 17, Fráncfort del Meno, Harri Deutsch, 2002, pp. 33-63.

14 Cf. p. 114r: «... Das erst/ daß ich den Römischen Bapst für den grossen Antichrist außgeben. Das ander/ daß ich die Freyheit der Religion bestritten und erhalten haben will. Das dritte/ daß mich der Erforschung und Wissenschafft der Zeit underfangen unnd undernommen hab».

15 Este último escrito es nombrado explícitamente en p. 147r, en el tratamiento de la sexta cuestión, que desarrolla por extenso el tema de la tolerancia y la problemática cronológica.

16 Kurtz Bedencken Von der Emendation dess Jahrs, pp. 116 ss. : «[...] im Christenthumb vor allen Dingen ob Christlicher Freyheit soll gehalten werden/ Solche aber des Gewissens Freyheit ist/ die allen Christgläubigen von dem HERRN Christo durch sein Blut erworben ist/ da wir nicht allein vom Gesätz der Sünden unnd deß Tods gefreyt seyn [...] sondern da wir auch von allen eusserlichen Satzungen und Verstrickung der Gewissen frey seyn/ daß wir uns nicht lassen widerumb in das Knechtisch Joch verknüpffen. [...] zu mercken von der weltlichen Oberkeit/ wie Christus das Haupt seiner Gemein sey/ und deß Geistlichen Reichs : Also sey die Oberkeit ein Haupt und Regent deß Weltlichen Reichs [...] . Dieweil dann der Christen Freyheit [...] nit ein Freyheit ist deß Fleisches/ sonder ein geistlich Freyheit deß Gewissens/ nicht ein solche Freyheit/ die der Oberkeit ihren Zustandt/ Ehr und gebürlichen Gehorsam entziehen wöll/ noch dem Menschen Ursach geben zu freueln/ ungehorsam unnd muhtwillig zu leben/ Sonder die Christum für das Haupt in Geistlichen 
y perturbar la paz pública. No se debe violentar las conciencias, tanto más cuanto que la fe es un don voluntario de Dios; obligar con "tiranía" a rendir un culto determinado en contra de la propia convicción es en definitiva una obra del Anticristo. ${ }^{17}$

Röslin vuelve sobre el tema de la libertad de religión de forma extensa en la respuesta a la "sexta cuestión". 18 Tras nuevas referencias a los efectos perversos que la violencia en materia de religión ha producido en los últimos cincuenta años en los Países Bajos y en Francia, por comparación con la tolerancia religiosa de que, por el contrario, hace gala el Turco, Röslin reitera que la religión no se ha de imponer con la violencia o por la espada. 19 Se ha de dejar a cada uno creer lo que quiera, esto es, el ámbito interior o espiritual debe quedar libre y la autoridad temporal debe castigar únicamente la conducta exterior punible:

die Leute/ so under ihnen [Príncipes y obispos] wohnen/ glauben möchten was sie wöllen/ welches doch der Türck nachlasset. So doch kein Oberkeit uber das Gewissen/ und die Seelen zu regieren hat/ sondern allein uber den Leib und Gut/ wie Christus sagt [...]. So muß man einen jeglichen glauben lassen/ was er will/ unnd sich des Glaubens halben nicht zweyen/ Die Oberkeit sehe zu/ wie Friede und Recht erhalten werde/ und lassen Glauben / Glauben seyn/ Will sie ander nicht Unglück auff ihren eignen Halß laden [...]. Nuhn gehört in die Straff nicht/ was ich glaube oder nicht glaube/ esse oder nicht esse/ sonder wer eusserlichen Friden bricht/ ein andern an Leib/ Ehre und Gut beschedigt/ der ist straffwürdig. Was innerlich ist/ unnd niemand zu Schaden gereicht/ soll das Schwerdt und die eusserliche Straffe zu Frieden lassen. ${ }^{20}$

Alemania, por consiguiente, no debe seguir y plegarse al designio maquiavélico del Papa y de los jesuitas. Le va en ello la paz civil y su libertad. Y Röslin opone a la política de la monarquía española en los Países Bajos y a la de Carlos IX de Francia, la moderación de que han hecho gala los tres últimos emperadores alemanes de la casa de Austria (Fernando I, Maximiliano II y el actual emperador Rodolfo II). Röslin se remite al discurso fúnebre pronunciado por Johannes Crato a Craftheim con ocasión de la muerte de Maximimiliano II (1576):

Sachen erkenne/ darinnen auch ihm mehr Gehorsam zu leisten sey/ dann dem Menschen/ nach Göttlichem Befelch. Die Oberkeit aber für das Haupt in weltlichen Sachen/ und in ihrem Ampt gehorsam».

17 Ibidem, p. 117r: «Diese den Frieden auffheben/ und Zerrütung und Unruh anrichten [...]/ welche die Freyheit der Religion auffheben/ unnd nicht gestatten wollen/ unnd also wider Gottes außgetruckten Willen und ernstlichen Befelch handlen. [...] Dann Gott wil sein Reich in den Gewissen mit keinem Zwang genötiget hal $<\mathrm{t}>\mathrm{en} / \mathrm{So}$ wol der Glaub nicht jedermans ding ist/ sonder ein freywillige Gab unnd Geschenck Gottes. [...] Daß man aber noch darüber in Göttlichen Sachen mit Tyranney fahren solt/ und zu grober greifflicher Abgötterey die Leut will zwingen unnd dringen [...] verbrennen/ Das ist deß Antichrists Werck».

18 Ibidem, pp. 142v-154r. El título de la cuestión es «Si el Papa conseguirá su objetivo de que mediante la reforma del calendario se suprima la paz religiosa y los príncipes puedan ser inducidos a la revuelta».

19 Ibidem, p. 146v: «die Religion will mit dem Schwert nicht verfochten seyn [...] man nemlich in Glaubens Sachen nicht mit Gewalt fahren soll».

20 Ibidem, pp. 147 r-v. 
Es meldet Iohannes Crato in oratione funebri Maximiliani deß letzten/ daß sich ihre Keyserlich Maiestet nie vermessen hab/ die Gewissen zu urtheilen unnd verdammen/ sonder er hab offentlich bekant/ nullum peccatum gravius esse quàm conscientiis velle dominari, daß kein grösser Sünd sey/ dann uber die Gewissen wöllen regieren und herrschen. So hab er auch dem König in Frankreich/ da er auß Polen gezogen [se trata de Enrique III] / zuverstehen geben/ daß die/ welche uber den Glauben herrschen wöllen/ sich wider Gott legen/ derhalben offt unnd nicht unbillich den Gewalt/ den sie sonst auff Erden haben/ auch verlieren/ unnd drumb kommen werden. ${ }^{21}$

Puede parecer en principio sorprendente que en este capítulo Röslin pase a desarrollar, como aval de su tesis de que la libertad de religión es una exigencia del futuro inmediato a la que vanamente intenta oponerse el Anticristo romano, unas consideraciones de carácter cosmológico-astronómico e histórico-cronológico. Pero esas consideraciones no hacen sino demostrar que la libertad de religión es una expresión de la purificación del cristianismo solidaria del curso providencial de la historia tal como ésta se despliega en conexión con las revoluciones celestes y en el periodo final en el que las proporciones numéricas que configuran su estructura se revelan ya como totalmente cumplidas y actualizadas. La libertad de religión es, en suma, una expresión del inminente triunfo de Cristo sobre el Anticristo.

Ese es el significado de las extraordinarias novedades celestes que se han sucedido desde la aparición de la nova de 1572 en Casiopea y sobre todo es lo que implica el nuevo periodo o revolución celeste que advendrá entre 1583 (fecha de la última gran conjunción de Júpiter y Saturno en el "trígono acuoso") y 1603, en que comenzará un nuevo periodo en "trígono ígneo", con la conjunción de Júpiter y Saturno en Sagitario, el séptimo y último desde la creación del mundo, que llegará a su fin tras haber sido creado también en un trígono ígneo. 22

21 Ibidem, p. 153v. Cfr. Oratio funebris de divo Maxaemiliano II. Imperatore Caesare Augusto, etc. à Johanne Cratone à Craftheim, Consiliario \& Medico Caesareo, etc. scripta, Bratislava, C. Scharffenberg, 1577, p. 8.

22 Kurtz Bedencken, pp. 148v-149r: «Unnd wird auch reden in diesem 1583. Jahr die grosse Coniunction und zusammen Kunfft der Planeten/ zu End deß Wesserigen Triangels im Zeichen der Fischen [...]. Diese aber jetzt angehende Coniunction/ so viel desto mehr zu bedeuten hat/ Dieweil sie zu End deß wesserigen Triangels geschicht/ unnd zu Anfang deß fewrigen/ nach dem mitlen unnd gleichen Lauff/ dergleichen dann innerhalb 800. Jahren einmal geschicht/ und ist der Himmel also gestanden zur Erschaffung der Welt/ Item/ vorm Sündtfluß/Item vor der Geburt Christi zu Anfang der Römischen Monarchi/ unnd Keiserthumb Julii Caesaris unnd Augusti/ Item/ zu Anfang deß Teutschen Keiserthumbs under Carolo Magno. Dieweil dann allwegen grosse Enderungen darauff erfolget/ und aber dieses von Anfang der Welt die siebende und letzte ist/ Wiewol sie erst auch dem wahren Lauff nach/ Anno 1642. vollkommen außlaufft/ unnd im Anfang deß fewrigen Triangels geschicht/ derwegen ein jeder darauß erachten kan/ was innerhalb solchen Jahren/ Nemlich von jetzt an biß in das 60 . oder 70. Jahr/ wir zu gewarten haben/ nemblich/ die allerletzten Enderungen/ mit welchen auch der Himmel unnd die Natur ihren Lauff unnd Werck/ darzu sie von GOTT bestimpt unnd verordnet/ verrichten werden/ erfüllen unnd zu Ende führen. Sonderlich aber dies künfftige zwenzig Jar wol warzunemmen sind/ dieweil es die Jar seindt mutationis aquei trigoni in igneum, in welchen allwegen sich die gröste Enderungen unnd Unruh/ begeben haben/ dann Anno 1603. geschicht erst die vollkommne coniunctio der Planeten in fewrigen Trigono». Sobre este tema véase Miguel A. Granada, «Kepler v. Roeslin on the Interpretation on Kepler's nova: (1) 1604-1606», Journal for the History of Astronomy, xxxvi, 2005, pp. 299-319 e idem, «After the nova of 1604: Roeslin and Kepler's 
Pero que el curso de la historia está llegando a su fin se demuestra también en un dato decisivo, según Röslin, que parece haber sido descubierto y formulado por primera vez por él. Se trata de que el número de emperadores de la cuarta y última monarquía (el imperio romano-germánico) se ha alcanzado ya con el actual emperador Rodolfo II, un número determinado por una proporción numérica con respecto a los regentes en los dos periodos anteriores (de ca. 2000 años cada uno): el periodo de "Vacío" anterior a Abraham y Moisés y el periodo de la "Ley". 23 El número de los "regentes" en estos dos primeros periodos era de $7 \times 3=21$ en el "Vacío", número que se doblaba en el segundo 14x3=42. En el tercer y último periodo, el de la "Gracia o el Evangelio", la proporción era triple con respecto al segundo: $42 \times 3=126$. Según Röslin este último número se había alcanzado con Rodolfo II y la suma de los tres daba un total de 189 , número perfecto $\left(7 \times 3^{3}\right)$, múltiplo a su vez de los dos números sagrados 3 y 7 . El cumplimiento de todos estos números, unido a los prodigios celestes y al cumplimiento de las revoluciones planetarias, lleva a pensar que los próximos años serán los de las grandes "mutaciones" (Enderungen) previas a la segunda venida de Cristo, entre ellas la implantación de la libertad de conciencia y de religión. ${ }^{24}$

Discussion on the Significance of the Celestial Novelties (1607-1613)», Journal for the History of Astronomy, xlii, 2011, pp. 353-390.

23 Obviamente Röslin se inspira en la famosísima "Tradición de la Casa de Elías", procedente del Talmud babilónico. Sobre ella véase Robin B. Barnes, Prophecy and Gnosis: Apocalypticism in the Wake of the Lutheran Reformation, Stanford, Stanford University Press, 1988 y también Miguel A. Granada, «Cálculos cronológicos, novedades cosmológicas y expectativas escatológicas en la Europa del siglo XVI», Rinascimento, 2a ser., 37, 1997, pp. 357-435 e idem, «La "tradición de la casa de Elías": Astronomía, cronología, historia», en Res Publica, en prensa.

24 Véase el amplio extracto de este importante pasaje recogido en el Apéndice. Estas proporciones numéricas habían sido planteadas por Röslin en su manuscrito, concluido en 1579, Speculum et harmonia mundi, Das ist Wellt Spiegel Erster Theil. La procedencia es confirmada indirectamente por el propio Röslin, que en un curriculum vitae personal manuscrito redactado en 1603-1604 (Ratio studiorum et operum meorum) afirmó que «Von dißenn Sachenn ich ettwas geschribenn [...], wie ich auch in meinem tractat vnndt bedenck vber die Emendation deß Calenders welchs alles genohmen auß dißem buch Speculi mundi et Ecclesiae, aber deßenn kaum der fünffzigste oder sechzigste theil ist»; véase nuestra edición en Miguel A. Granada, «Helisaeus Röslin on the eve of the appearance of the nova of 1604: his eschatological expectations and his intellectual career as recorded in the Ratio studiorum et operum meorum (1603-1604)», Sudhoffs Archiv, 90, 2006, pp. 75-96 (el pasaje citado en p. 94). Dichas proporciones figuraban también en un manucrito poco posterior, redactado en 1580 con el titulo De potestatibus Orbis Christiani/ et Politicis et Ecclesiasticis./ DISCURSUS:/ Ex summorum in Regnis Monarcha-/ rum et in Ecclesia Romana Praesulum/Catalogo, miram Harmoniam ob ocu-/los

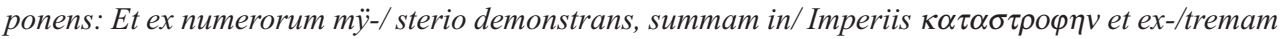
imminere mutationem:/ Cum/ Thesibus Chronologicis. El manuscrito De potestatibus Orbis Christiani, cuya existencia y autoría rösliniana nos había sido señalada generosamente por Carlos Gilly, se encuentra en la Württembergische Landesbibliothek de Stuttgart (Cod. hist. $\left.4^{\circ} 31\right)$ y ha sido objeto por parte nuestra de un amplio estudio. Véase Miguel A. Granada, «Helisaeus Roeslin's Chronological Conception and a New Manuscript Source», Early Science and Medicine, 18, 2013, pp. 213-265. Merece finalmente ser notado que esta referencia a la suma total de 189 , equivalente a $7 \times 3^{3}$, no aparece en el manuscrito De potestatibus de 1580 y tampoco en el manuscrito Speculum et harmonia mundi. 
En 1597, el mismo año de la aparición del De opere Dei creationis, Röslin publicó un Tractatus meteorastrologiphysicus, 25 en el que proponía una nueva teoría cometaria en oposición a la tradicional doctrina aristotélica. ${ }^{26}$ Pero, además del componente astronómicocosmológico, este tratado ofrecía una interpretación del significado y efectos de los cometas a partir de una consideración conjunta de los cometas aparecidos entre 1556 y 1596, especialmente el de 1580. La posición intermedia de este cometa entre 1556 y 1604, así como la vinculación de su trayectoria con la nova de Casiopea de 1572 y el próximo advenimiento del trígono ígneo con la gran conjunción de Júpiter y Saturno en Sagitario en diciembre de 1603, llevaron a Röslin a anunciar el comienzo de una «transformación general» (universal Catastrophe) en los asuntos humanos. ${ }^{27}$ Curiosamente, ninguna referencia se hacía en este tratado a la libertad de religión y de conciencia como un componente central de esa katastrophé. Sin embargo la manuscrita Ratio studiorum et operum meorum de 1603 o 1604 se refiere a este tratado y señala los componentes religiosos del proceso, mencionando la unificación de Inglaterra y Escocia con el acceso al trono de Inglaterra de Jacobo I como una muestra de los nuevos tiempos. ${ }^{28}$

El Historischer/ Politischer und Astronomischer naturlicher Discurs Von heutiger zeit Beschaffenheit/ Wesen und Standt der Christenheit de 1609 aclara la situación. ${ }^{29}$ Se trata de un importante tratado en el que Röslin, polemizando con Kepler a propósito de la nova de 1604 en Serpentario y respondiendo a las críticas de Kepler a su pronóstico de la universal Catastrophe anunciada para $1604,{ }^{30}$ precisa algunos puntos. A la referencia a la unión polí-

25 H. Röslin, Tractatus meteorastrologiphysicus. Das ist, Aus richtigem lauff der Cometen/ zusammenleuchtung der Planeten/ etlicher Herrn Nativiteten/Natürliche Vermütungen und ein Weissagung. Von Veränderungen der Regimenten in Königreichen unnd Fürstenthumben der Welt und andern wichtigen Wunderlichen/ Politischen/Weltlichen unnd Kriegssachen/So sich Kurtz künfftig innerhalb wenig Jaren begeben werden/von jetzt an biß 1604. nach Christi Geburt unnd etwas hernach/Allen Christlichen Potentaten unnd hohen Oberkeiten unnd jedermenniglichen zur Warnung unnd Auffmunterung, Estrasburgo, Bernahrt Jobins Erben, 1597.

26 Sobre la teoría cometaria de Röslin véase ahora Miguel A. Granada, «La théorie des comètes de Helisæus Roeslin», en Miguel A. Granada - Édouard Mehl (eds.), Nouveau ciel, nouvelle terre: La révolution copernicienne dans l'Allemagne de la Réforme (1530-1630), París, Les Belles Lettres, 2009, pp. 207-244 (220-224).

27 Tractatus meteorastrologiphysicus, cit. (nota 25), pp. 14r ss. Cf. Granada, «La théorie des comètes de Helisæus Roeslin», cit. (nota 26), p. 224.

28 Ratio studiorum: «Dißer tractat ist vor 6 Jahren zu Straßburg getruckt [...] vnndt daß die Königrich Schottlandt vnndt Engellandt vnder ein haupt kommen, ist ein hohe wichtige sach vndt ist in keinen historien zufindenn, vnndt ist daß erste stuck, so das neüwe sternn möchte bedeüt haben. Dann von dißer Zeitt an man erst sehen würdt, was der neüwe stern de Anno 1572 vnndt 1573 bedeüt hab deßenn bedeütung reicht biß man zehlenn würdt 1642 vnndt 1643. Hiezwischenn würdt die Zeitt sein der aller größten Verenderungen, der Reichenn der Weldt, der Lettstenn verenderung vnndt würdt sich erfüllen was noch zuerfüllenn vbrig ist in denn Prophetenn», en Granada, «Helisaeus Röslin on the eve of the appearance of the nova of 1604 ...», cit. (nota 24), p. 94.

29 H. Röslin, Historischer/ Politischer und Astronomischer naturlicher Discurs Von heutiger zeit Beschaffenheit/ Wesen und Standt der Christenheit und wie es ins künfftig in derselben ergehn werdel Aus anleitung dero von Anno 1600. her am hohen Himmel erschienenen grossen Wunderzeichen/sonderlichen dess Cometens anno 1607. genommen, Estrasburgo, Conrad Scher, 1609.

30 Sobre este importante punto remitimos a nuestros trabajos citados en la nota 22. 
tica de Escocia e Inglaterra se unen ahora los Países Bajos, de quienes se subraya su pretensión de plena libertad frente a España y su defensa de la "libertad de religión", y muy significativamente Francia. Röslin aplaude la política de pacificación de Enrique IV con las siguientes palabras: «Er [Enrique IV] die unruhen und den Krieg von Jugend auff erfahren/ und das wenig glück und Heil dabey ist/ derwegen er kurzumb frieden in seinem Land haben will/ und damit dieser bestehen mög/ auch freyheit der religion haben wil/ welches dann das einig mittel zum frieden/ und sonst kein anderes ist». 31

\section{El nuevo cielo y la libertad de religión}

En 1612, con ocasión de la elección y coronación como emperador de Matías I (tras la abdicación de su hermano Rodolfo II), Röslin publicó Ein Tabella des Welt Spiegels. Se trataba de una hoja de gran formato [Figura 1] que iba acompañada de un tratado de treinta páginas en el que Röslin resumía lo fundamental de su manuscrito Speculum et harmonia mundi. ${ }^{32}$ Nuestro médico reiteraba que el momento contemporáneo era el de la décima y última edad del mundo, el del final de la "séptima revolución de los planetas" y el comienzo de la octava (con el nuevo y último periodo de 'trígono ígneo' repetido cada 800 años), en suma: el momento final en el que el mundo (no sólo el Islam, sino también el cristianismo) será castigado y vencerá «el reino de Cristo y la verdad». Es lo que significan «las nuevas estrellas que han aparecido en el trígono ígneo y el mismo trígono ígneo que ahora empieza». ${ }^{33}$ ¿De qué estrellas se trata? Obviamente, la primera idea que viene a la mente es las dos grandes novas de la época: la de Casiopea en 1572 y la del Serpentario en 1604 . Y el mismo Röslin parece avalarlo poco después cuando dice que «esas dos grandes estrellas son los signos máximos que deben aparecer antes del último día [...] las grandes estrellas en el cielo más alto, en el firmamento, que ha permanecido cada una durante todo un año».34 Y sin embargo la nova de Casiopea (1572-74) se manifestó bastantes años antes del nuevo trígono ígneo. Aunque se podría pensar según eso que Röslin piensa en otra estrella acompañando a la nova del Serpentario, lo más probable es que su expresión en este pasaje no haya sido del todo precisa. En cualquier caso, lo que añade a continuación viene en nuestro

\footnotetext{
31 Historischer/ Politischer und Astronomischer naturlicher Discurs, cit. (nota 29), p. 64. Cf. ibidem, pp. 41-42.

32 H. Röslin, Zu Ehrn der Keyserlichen Wahl und Krönung Matthiae deß I. [...] Ein Tabella des Welt Spiegels. Darinnen Geistliche Göttliche unnd Politische Weltliche Sachen in einer Harmonia und Vergleichung gegen einander gestellt werden/ nach den sieben Revolutionen der Planeten und Zehen Altern von Anfang der Welt biß zu Endt/das darauß zu ersehen/in was Zeiten wir seyen/ und was noch zuerfüllen ubrig, Fráncfort del Meno, Johann Dieterich de Bry, 1612. La Tabella de Röslin fue reproducida, con muy pocos cambios y añadidos y traducida al latín, en la tabla Speculum mundi que Johann Heinrich Alsted publicó en su Thesaurus chronologiae, Herborn, 1624, pp. 324-325. Sobre este significativo hecho, que si no estamos equivocados no había sido señalado hasta ahora, nos hemos extendido en nuestro trabajo «Helisaeus Roeslin's Chronological Conception and a New Manuscript Source», cit. (nota 24), pp. 253-255.

33 Ibidem, p. 14.

34 Ibidem pp. $16 \mathrm{~s}$.
} 
auxilio para introducir en el cuadro otras estrellas: «y desde entonces todavía más estrellas, más pequeñas, han sido observadas en el cielo, por lo que son las máximas señales que deben acontecer antes del último día. De estas estrellas [hablo] en el librito Mitternächtige Schiffarth, publicado en 1611 en Oppenheim y en el librito Discurs, publicado en Estrasburgo en 1609; ambos pueden encontrarse todavía en Fráncfort». 35

De qué estrellas se trata lo veremos a continuación, pero antes queremos precisar que el tiempo presente es para Röslin el de las últimas transformaciones, porque la cronología del mundo toca a su fin. El mundo sobrepasa ya los 5600 años de existencia y los 6000 años no se alcanzarán «porque Cristo nuestro Señor ha dicho también que los días del fin serán acortados» (Mateo 24, 22). Es cierto que inquirir con precisión el momento del fin nos ha sido prohibido por Dios (reconoce Röslin, aludiendo a Mateo 24, 36), pero por otra parte (añade) Cristo reprochó a los judíos que no se preguntaran por el tiempo del fin. ${ }^{36}$ Röslin justifica de esta manera su indagación cronológica de las postrimerías. Y en esta dirección acumula todas sus indagaciones en el Speculum et harmonia mundi, no sólo las evidencias procedentes del curso y periodos de la maquinaria celeste, sino también las provenientes del campo de la historia sagrada y profana, como por ejemplo la correspondencia o harmonía entre las 42 generaciones comprendidas entre Abraham y Jesús (Mateo 1, 17) con los 42 emperadores entre Augusto y Constantino, entre Constantino y Carlomagno y entre Carlomagno y «la actualmente reinante Majestad Imperial».37 Ésta es tan sólo una entre otras correspondencias o "proporciones numéricas" ya a punto de cerrarse y cumplirse en la historia que Röslin sintetiza en esta obra ${ }^{38}$ dedicada al nuevo emperador de la casa católica de Habsburgo para mostrar que el tiempo de las grandes transformaciones del fin está ya próximo. Hemos de decir, no obstante, que toda la retórica de obras manuscritas y polémicas anteriores acerca del Anticristo romano y la identificación del fantasmal imperio germánico con el reino del Anticristo romano están ausentes de la Tabella, acaso como inapropiadas para una obra dirigida al emperador católico de la casa de Habsburgo. 39

\footnotetext{
35 Ibidem, p. 17: «und seythero noch mehr kleinere Sternen im Himmel vermerckt worden/ derowegen die gröste Zeichen seynd/ die vorm jüngsten Tag geschehen können. Von diesen Sternen im Büchlein der Mitternächtigen Schiffarth zu Oppenheim außgangen Anno 1611. Vnd im Büchlein Discurs zu Straßburg 1609. außgangen/ beyde noch zu Franckfurt zu finden».

36 Ibidem, p. 14. Esta acusación que se aplicaba también a los cristianos contemporáneos figuraba en el prólogo al Speculum et harmonia mundi. Véase sobre este punto Miguel A. Granada, «Helisaeus Röslin: chronologie, astronomie, histoire... et prophétie (4 Esdras et l'avènement du royaume du Christ)», en Édouard Mehl, ed., Astronomie, chronologie, histoire: Cosmologie et décompte du temps, de la Renaissance à l'âge classique, Paris, Les Belles Lettres, en prensa.

37 Ibidem, pp. 19 s. Röslin emplea la misma fórmula que en el Kurtz Bedencken de 1583 y entonces designaba a Rodolfo II. La ambigüedad no se aclara. Sobre las oscilaciones de Röslin en la determinación del emperador que completa el número, vacilación que aparece unida a la existencia de emperadores ‘cismáticos' o irregulares, véase Granada, «Helisaeus Roeslin's Chronological Conception and a New Manuscript Source», cit. (nota 24).

38 Así, por ejemplo, en el ámbito de la Iglesia los 112 papas entre Silvestre I (en la época de Constantino el Grande) y el último obispo de Roma, en correspondencia con los 112 sumos sacerdotes hebreos entre Aaron y la época de Herodes. Cf. Zu Ehrn der Keyserlichen Wahl und Krönung Matthiae deß I. [...] Ein Tabella des Welt Spiegels, cit. (nota 32), pp. 22 ss.

39 Sobre estos puntos remitimos a nuestro trabajo ya citado (nota 36) «Helisaeus Röslin: chronologie, astronomie, histoire... et prophétie (4 Esdras et l'avènement du royaume du Christ)».
} 
En el último capítulo de la obra («De los dos grandes imperios al final del mundo, el cristiano y el mahometano y lo que se ha de deducir de ello») Röslin vuelve sobre la profecía de 4 Esdras, libro que Röslin tiene por canónico y del que había dado una interpretación en un tratado manuscrito en alemán que se ha conservado en la traducción latina de Karl Widemann (1555-1637), médico schwenckfeldiano y paracelsiano de la ciudad de Augsburgo. ${ }^{40}$ Recuerda que todavía quedan dos cabezas del Águila tricéfala de que habla el libro profético (caps. 11 y 12): la turca, que ha eliminado por la espada al imperio romano de Oriente, y la romano-germánica. ${ }^{41}$ No cabe duda de que el Turco morirá por la espada, al igual que por la espada destruyó al imperio bizantino (4 Esdras 12, 27-28). Sólo queda, pues, el imperio de Occidente. Röslin, acaso porque su obra se dirige a un emperador alemán católico, silencia su identificación del imperio con el Anticristo romano y la constatación de que el poder del emperador ha quedado reducido a un «vacuus et inanis titulus».42 Retoma, sin embargo, el motivo de las dos plumas contrarias (católicos y protestantes) que permanecen hasta el fin produciendo la escisión y los enfrentamientos permanentes. 43 Pero Röslin añade ahora algo nuevo, que no figuraba en su interpretación anterior de la profecía de Esdras y en alguna medida la corrige: cuatro plumas contrarias (que antes se habían identificado con godos y vándalos y con longobardos y exarcas bizantinos) permanecen en el último tiempo como fuente de discordia y tumulto: las cuatro sectas cristianas enfrentadas de católicos, luteranos, calvinistas y anabaptistas-arrianos. Y Röslin remite de nuevo al lector (y al nuevo emperador) a sus obras inmediatamente anteriores: la Mitternächtige Schiffarth de 1611 y el Discurs de 1609.44 De esta manera volvemos al motivo de las estre-

40 Interpretatio Mystica et Vera in Quartum librum Esdrae Prophetae, British Library, MS Hologr. 2.D.XX. Hemos estudiado este comentario en el trabajo citado en la nota anterior. Sobre Widemann y su colección de manuscritos, entre los que figuraban numerosos tratados de Röslin, véase Carlos Gilly, Adam Haslmayr: Der Erste Verkünder der Manifeste der Rosenkreuzer, Ámsterdam, In de Pelikaan, 1994, pp. 106-117.

${ }^{41}$ Zu Ehrn der Keyserlichen Wahl und Krönung Matthiae de $\beta$ I. [...] Ein Tabella des Welt Spiegels, cit. (nota 32), pp. $25 \mathrm{~s}$.

42 Interpretatio Mystica et Vera in Quartum librum Esdrae Prophetae, cit. (nota 40), p. 23 r. Un indicio, sin embargo, de la persistente valoración negativa del papado la tenemos en p. 25 , donde la «monarquía romana del Papa» es identificada de pasada con la bestia de Daniel 7.

${ }^{43}$ Zu Ehrn der Keyserlichen Wahl und Krönung Matthiae de $\beta$ I. [...] Ein Tabella des Welt Spiegels, cit. (nota 32), pp. 26 s.: «[...] welches dann allbereyt erfüllet/ daß die Christenheit zertrennet ist in zwo Partheyen/ als Bäpstische unnd Protestierende/ beyde under zweyen scheinbaren guten Namen/ als Catholische unnd Evangelische/ beyde Partheyen hefftig wider einander/ daß die Christenheit also geschwächt/ und ihre Reich aller Unruhe voll seynd/ wie der Prophet Esdras sagt». Bajo la apariencia de cristiandad la realidad es, por tanto, profundamente anticristiana y ello pone de manifiesto, para el que es capaz de ver más allá de la apariencia, el triunfo del Anticristo.

44 Ibidem, p. 27: «Zu Anfang aber deß 12. Capituls [cf. 4 Esdras 12, 21: "adpropinquante tempore medio, quattuor autem [pennae] servabuntur in tempore, cum incipiet adpropinquare tempus eius ut finiatur"] wirdt der Christenheit dieser letzten Zeit under vier Feddern gedacht/ welcher Regierung schwach unnd aller Unruhe voll seye: Durch welche vier Feddern anders nichts verstanden/ dann die vier Partheyen in Glaubens Sachen zu unser Zeit/ als die Papisten/Lutherischen/ Calvinischen/ und ubrige allerhandt Secten der Widertäuffer/ auch Arrianer. Von welchen Sachen man findet in meinem Büchlein der Mitternächtigen Schiffarth/Anno 1611 zu Oppenheim außgangen/ auch im Discurs von 
llas (Sterne), aparte de las dos grandes novas (supernovas en términos actuales), visibles en el cielo desde los comienzos en 1603 del nuevo y último periodo de trígono ígneo.

Las estrellas nuevas de que habla Röslin son, en primer lugar, una presunta nova (en este caso de la cuarta magnitud) en la constelación de la Osa Mayor y, en segundo lugar, la nova de tercera magnitud en el Cisne, aparecida en 1600 y todavía visible en el cielo, sobre la cual Kepler había escrito un informe publicado en el interior de su De stella nova in pede Serpentarii de 1606.45 La primera descansa en un malentendido de Röslin, que éste se resiste a abandonar, obsesionado como está por registrar el máximo número posible de evidencias de que el cielo está realmente cambiando en el momento contemporáneo. 46

Por lo que se refiere a la nova del Cisne, Röslin recuerda en la Mitternächtige Schiffarth que dicha constelación es llamada también "Gallina" e «informa del estado de las iglesias y de la religión [cristiana] en todo el mundo, así como acerca de su cabeza, Cristo nuestro Señor». ${ }^{47}$ La conexión es avalada por la referencia explícita a la declaración de Cristo en la Escritura: «wie er [Cristo] sich dann selber dahin gemeynt hat/ da er sagt/ "wie offt hab ich euch versamlen wöllen als ein Hänne ihre Hünckeln unter ihre Flügel versamlet" [Mateo 23, 37: «¡Cuántas veces quise reunir a tus hijos a la manera que la gallina reúne a sus pollos bajo las alas!»]».48 Llama la atención que Röslin no haya hecho mención también del pasaje paralelo de 4 Esdras 1, 30 («ita vos collegi ut gallina filios suos sub alas suas» [«Así os reuní, como la gallina reúne a sus pollos bajo sus alas»]), que según su cronología es anterior y por tanto una profecía de Cristo y del cristianismo. 49 Es muy posible que no le haya venido a la mente en el momento de escribir estas líneas, pero en cualquier caso la presencia en 4 Esdras de este motivo es para nosotros muy significativa dada la referencia inmediatamente posterior (en la Tabella des Welt Spiegels, como acabamos de ver) a 4 Esdras y a las cuatro plumas contrarias del Águila como representando las cuatro confesiones cristianas enfrentadas en universal discordia, remitiendo además al lector precisamente a este desarrollo en la Mitternächtige Schiffarth.

den Cometen Anno 1609. zu Straßburg außgangen/ welche beyde noch zu Franckfurt zu bekommen seynd».

45 Johannes Kepler, De stella tertii honoris in Cygno, quae usque ad annum MDC fuit incognita, necdum extinguitur, Narratio astronomica, en J. Kepler, Gesammelte Werke, M. Caspar (ed.), Múnich, Beck, 1937-2010, (en lo sucesivo $J K G W$ ), vol. I, pp. 293-311.

46 En realidad se trataba de una estrella que, según Kepler, existía en el cielo desde el comienzo del mundo y había sido identificada por Brahe en su ampliación del catálogo estelar recogido en su obra Astronomiae instauratae progymnasmata, publicada en 1602. Sobre este punto véase Granada, «After the nova of 1604: Roeslin and Kepler's Discussion on the Significance of the Celestial Novelties (1607-1613)», cit. (nota 22), p. 377 nota 19.

47 H. Röslin, Mitternächtige Schiffarth Von den Herrn Staden inn Niderlanden vor XV. Jaren vergebenlich fürgenommen, wie dieselbige anzustellen, daß man daselbst herumb in Orient und Chinam kommen möge, zu sonderen der Christenheit, sonderlich Teutschlands Nutzen und Wolfart, Oppenheim, durch H. Gallart in Verlegung Joh. Theod. de Bry, 1611, p. 98. Para lo que sigue remitimos a Granada, «After the nova of 1604: Roeslin and Kepler's Discussion on the Significance of the Celestial Novelties (1607-1613)», cit. (nota 22), pp. $371 \mathrm{~s}$.

48 H. Röslin, Mitternächtige Schiffarth, cit. (nota 47), p. 98.

49 Recordemos que la crítica moderna considera 4 Esdras 1 y 2 un texto independiente (denominado 5 Esdras), redactado en griego por un autor cristiano en el siglo II d. C. y con una fuerte influencia del evangelio de Mateo. 
Röslin, además, recuerda a continuación que los alemanes llaman a menudo a esa constelación "Cruz" y como tal la representan. Y no se olvida de indicar que el mismo Kepler en su De stella nova había dicho que «si un cristiano quisiera forjar (fingere) nuevas imágenes [a partir de la aparición de la nova en la imagen de la constelación], hallaría allí la figura del crucificado con la cabeza inclinada», pues la nova - decía Kepler- representaba el pecho del crucificado y la estrella en el pecho del cisne, hacia la izquierda, la cabeza de Cristo. ${ }^{50}$ Pero si para Kepler no cabía duda de que las imágenes celestes eran producto de la imaginación, representaciones puramente convencionales de un cielo estelar que básicamente permanecía inmutable desde la creación del mundo, para Röslin la nova en el Cisne (constelación que se había apresurado también él a registrar como imagen de Cristo) ${ }^{51}$ o en la Gallina había transformado realmente, por una milagrosa intervención de Dios, la figura real de la Cruz en la imagen real de Cristo crucificado manifiesta ahora a la humanidad, puesto que la nova representaba el corazón de Cristo. Y a su alrededor, las cuatro estrellas en la cruz (coincidiendo con las estrellas en el pico, las alas y el vientre del Cisne) representan las cuatro iglesias trinitarias (Papistas, Luteranos, Calvinistas y Anabaptistas), entre las cuales Cristo había reaparecido - como el corazón - para significar que Él era el centro y punto de unión de todas ellas, para denunciar la intolerancia y anunciar la futura "libertad de religión", bajo la cual todas las iglesias vivirán en armonía. 52 Notemos que aquí Röslin anuncia un rasgo de la "catastrophé universal" que viene a superar el estado anterior de discordia y enfrentamiento.

La fecha de publicación (1611) de esta obra permitió a Röslin responder a las novedades celestes reseñadas por Galileo en su Sidereus nuncius de 1610 y comentadas por Kepler en su Dissertatio cum nuncio sidereo de ese mismo año. Röslin sólo toma en consideración la novedad de los cuatro planetas mediceos. Aceptada su realidad frente a Martin Horky,53 Röslin se inclina a pensar, frente a Galileo y Kepler, que se trata de creaciones nuevas y extraordinarias de Dios, puestas en el cielo en el mismo momento en que Galileo ha dirigido hacia allí el telescopio, tanto más cuanto que no se han apreciado otras lunas en torno a los otros planetas. ${ }^{54}$ El problema por tanto a indagar era: ¿qué quiere Dios señalar a los hom-

$50 J K G W$, vol. I, p. 297. 25-30.

51 Mitternächtige Schiffarth, cit. (nota 47), p. 98: «So ist auch ein Schwan der aller schönste weisseste Vogel/ wirt unserem Herrn Christo in diesem verglichen/ daß die Physici und Naturkündiger schreiben/ so ein Schwan sterben wölle so geschehe solches mit vorgergehendem lieblichsten Gesang/ also unser Herr Christus am Stammen des Creuzes vor seinem Abschied die sieben allerlieblichste und der ganzen Welt heilsamste Wort gesprochen».

52 Ibidem, p. 110: «Dann das Bild deß Salvators mit den vier Sternen oben im Himmel das stehet feste und fehlet nicht/ So müssen die vier Religionen der Christenheit unten in der Welt im Reich seyn/ [...] und hat sich der fünffte und newe Stern deß Salvators mitten eingesetzet/ anzuzeigen/ daß der HERR Christus mitten im Handel sey/ und wircken wölle wo Freyheit der Religion sey, nicht zu Zwang und Trang sey».

53 Véase M. Horky, Brevissima peregrinatio contra Nuncium sidereum nuper ad omnes philosophos et mathematicos emissum, Mutinae [Modena] 1610, reprint en Galileo, Opere, edición de A. Favaro, vol. iii/1, Florencia, G. Barbèra, 1930, pp. 127-145.

54 Mitternächtige Schiffarth, cit. (nota 47), p. 119: «So sich aber um die ubrige Planeten kein newer [Stern] finden solte/ so wil ich diese umb den Iovem darfür halten/ daß sie gantz new seyen/ und zu unsern Zeiten erst von Gott an Himmel gestelt seyen/ wie diese newe in Ursa und Cygno», cursiva nuestra. 
bres con estas novedades prodigiosas? Röslin creía que, al igual que la nova del Cisne y de acuerdo con el papel que los astrólogos asignan a Júpiter como indicador en el campo de la religión, los cuatro planetas mediceos significaban los cuatro partidos religiosos de la Cristiandad y su relación con Cristo en el nuevo periodo final de la historia del mundo, bajo el gobierno del León de 4 Esdras, esto es, de Cristo:

estos cuatro nuevos planetas en torno a Júpiter significan exactamente lo mismo que nos han expuesto las estrellas en el Cisne, concretamente los cuatro partidos existentes en los asuntos religiosos, repartidos por todo el mundo o especialmente en el caso de Alemania, pues Júpiter es el planeta a partir del cual los astrólogos establecen su juicio en los asuntos del espíritu y de la religión.55

Vemos así que la cuestión para Röslin no era tanto revelar o descubrir la configuración permanente del mundo, estable desde su creación por Dios, como descubrir los cambios que se estaban produciendo en el mundo por la acción extra-ordinaria de Dios en conexión con el tiempo escatológico que ahora se hallaba en pleno despliegue. Lo que importaba, entonces, era descubrir el significado de los cambios que el mundo estaba experimentando y ese significado sólo era transparente a la luz de la cronología ${ }^{56}$, de las profecías y del examen minucioso de la historia en el "espejo del mundo y de la iglesia" con las correspondencias y harmonías que ponía de manifiesto. En esa línea, Röslin podía evocar la presunta observación por Kepler del tránsito solar de Mercurio en 1609 (800 años, además, después de que hubiera sido observado por el astrónomo de Carlomagno $)^{57}$, no por sus implicaciones en el plano cosmológico, sino justamente por su significado histórico, puesto que «tiene que significar algo, ya que es raro e infrecuente; también porque con los cuatro nuevos planetas [mediceos] todavía es más raro y nunca visto antes por nadie, por lo cual tal cosa Dios no la ha dejado suceder sin ningún propósito, sino que lo ha expuesto para informarnos acerca de las cosas anteriormente indicadas».58 Es verdad que ahora la denuncia del reino del Anticristo romano y el anuncio de su fin próximo parecían haber quedado relegados a un

55 Ibidem, p. 118: "diese vier newe Planetsternen umb den Iovem eben das bedeuten/ was die im Schwanen uns fürgetragen/ nemlich die viererley Partheyen in Religionssachen/ nach der gantzen Welt ausgetheilt/ oder insonderheit nach Teutschland gericht/ Dann Iupiter je dieser Planet ist auß welchem die Astrologi das Iudicium von Geistlichen und Religionssachen nemmen".

56 El Prodromus dissertationum chronologicarum, publicado en Fráncfort del Meno en 1612, iba a reiterar la primacía de la cronología constantemente afirmada por Röslin en sus escritos y correspondencia. Véase H. Röslin, 1572. Prodromus. 1604. Dissertationum Chronologicarum. Das ist/ Der Zeit Rechnung halben ein außführlicher und gründtlicher Teutscher Bericht [...] Das nemblich den Jahren und dem Alter unsers Herrn unnd Heylandts IESU CHRISTI nicht fünff Jahr zuzusetzen seyen/ wie I. Keys. Majest. Mathematicus Iohann Keplerus haben wil/ sonder mehr nicht als fünff viertheyl Jahr/Also/das CHRISTUS warhafftig im vierthalben und dreyssigsten Jahr seines alters gelitten hab, Fráncfort, del Meno, Matth. Beckern in Verlegung Johann Theodor de Bry, 1612, p. 16 r: «welches [la cronología] dann das höchste studium und uber alle/ und gleich alles mit einander recapitulirt und begreifft».

57 Véase J. Kepler, Phaenomenon singulare seu Mercurius in Sole, Leipzig, Thomas Schürer, 1609, en $J K G W$, IV, pp. 80-98. Cf. Granada, «After the nova of 1604: Roeslin and Kepler's Discussion on the Significance of the Celestial Novelties (1607-1613)», cit. (nota 22), p. 363 y nota 82, 373.

58 Mitternächtige Schiffarth, cit. (nota 47), pp. 119 s.: «das etwas zu bedeuten hab/ weil es rarum und insolens, ganz seltzam und ungewohnet ist/ Also weil solches mit den vier newen Planeten noch seltza- 
segundo plano y en su lugar había emergido como motivo preferente, si no central, el tema de la "libertad de religión" y de la "libertad de conciencia" como el signo de los nuevos tiempos que, en consonancia con la segunda venida de Cristo, estaban empezando a abrirse paso en Europa superando la nefasta fractura religiosa. ${ }^{59}$ No era, ciertamente, cosa de escasa trascendencia y afirmando esos valores Röslin estaba, sin duda, dando un testimonio y una lección de innegable valor. Ello no debe hacernos olvidar, sin embargo, que el fin del imperio romano en su última versión germana (tan estrechamente asociada al papado) y el advenimiento del reino de Cristo debían estar inevitablemente acompañados de «gran agitación, de castigo y de azotes», 60 como en las anteriores destrucciones de Roma en las invasiones bárbaras que pusieron fin al antiguo o primer imperio romano y que habían tenido una réplica contemporánea en la toma de Constantinopla (1453) y en el saco de Roma (1527).61 En cualquier caso el reloj del mundo y de la historia estaba llegando a su término final, como ponía de manifiesto la disciplina fundamental e incluso, podríamos decir con justicia, reina de las ciencias: la cronología.

\section{APÉNDICE}

Lambertus Floridus Plieningerus (=Helisaeus Röslin)

Kurtz Bedencken Von der Emendation dess Jahrs/ durch Bapst Gregorium der XIII. fürgenommen/ und von seinem Kalender/nach ihm Kalendarium Gregorianum perpetuum intituliert Heidelberg, Johan Spies, 1584, pp. 149v-151r.

$[149 v]$ Es wirdt zwar ein Schriftlich Bedencken umbgetragen/ welches an Keys. Majestat/ hochlöblichster Gedechtnuß Maximilianum den andern gestellt/ unnd ubergeben worden ist/ darinn auß Vergleichung und Analogia der Succession und Glider der Zeit deß Ledigen und Gesatzes (Vacui \& Legis) erwiesen wird unnd demonstriert/ daß die Succession und Zahl der Keyser/ als der dritten Zeit Gratiae vel Evangelii auch erfüllt sey und zu End lauff. 62

mer und zuvor niemahlen gesehen worden/ derwegen solches nicht vergeben Gott geschehen lassen/ sondern solches dargestellt/ uns obermelter Sachen halber zu berichten».

59 El Prodromus dissertationum chronologicarum lo iba a proclamar rotundamente. Cf. Prodromus, cit. (nota 56), sig. a iii v ${ }^{\mathbf{o}}$ : «diese unsere jetzige Zeit/ die Zeit seye der Freyheit der Religion/ und dieses also seyn und zugelassen werden müsse».

60 Ibidem, p. 29: «Derowegen darauß zu schliessen/ daß der dritte und letzte Fall deß letzten Römischen Reichs [...] nit fern mehr seyn könne/ sondern innerhalb jetztermeldten Jaren geschehen/ und zu endt lauffen werde/ mit grosser Unruhe/ und Straffe unnd Plagen: Wie es im alten Römischen Reich im dritten Fall auch ergangen ist. Welchs sich alles wol vergleichet mit der Zahl unnd Namen der Keyser/ sie zum theil verlauffen/ zum theil zu erfüllen uberig seynd/ wie die Tabula vor Augen stellet».

61 Ein Tabella des Welt Spiegels, cit. (nota 32), pp. 28 s. Cf. p. 29, donde la tercera destrucción de Roma (en 546 y 549), a cargo del rey ostrogodo Totila 1296 años después de la fundación de Roma, remite la tercera amenaza sobre la ciudad para el año 1628.

62 Röslin, que escribe aquí bajo pseudónimo, se refiere a que hizo llegar al emperador Maximiliano II una memoria escrita en la que se exponía esta doctrina de las proporciones numéricas de los regentes 
Dann wie die Zeit deß Ledigen in sich begreifft 21. Successiones und Geburten/ von Adam biß auff Loth (under welchem die Zeit deß Ledigen auffhört mit der Zerstörung Sodoma und Gomorrha) doch nach dreyen underschiedlichen Enderungen/ daß nemblich zum ersten 7. seyn von Adam biß auff Enoch/ welcher verzuckt/ zum andern 7. von Enoch biß auff Eber/ under welchem die Erden nach der Sündtfluß außgetheilt/ zum dritten 7. von Eber biß auff Loth/ davon in Genesi/ aber in der Zeit deß Gesatzes seyn noch so viel/ nemblich 42. Successiones und Glieder von Abraham bis auff Christum/ da die Beschneidung sampt dem Gesatz auffgehoben/ mit der Zerstörung Jerusalem/ unnd auch außgetheilt nach dreyen grossen Enderungen/ daß da zum ersten seyen 14. Successiones von Abraham biß auff David/ under welchem das Königreich Juda angefangen/ zum andern/ 14. von David biß auff die Babylonische Gefängnuß/ das End deß Königsreichs Juda/ zum dritten 14. von der Babylonischen Gefängnuß biß auff Christum/ davon im ersten Capitel Matthei.

Also spricht obermelter Author/ sollen in der dritten Zeit deß Evangelii dreymal so viel Successiones der Keyser seyn, als in der ander Zeit des Gesatzes gewesen seyn/ nemblich 126. Keyser. Auch außgetheilt nach dreyen grossen underschiedlichen Enderungen/ unnd finden sich also zum ersten 42. Keyser von Julio Caesare dem ersten Römischen Heydnischen Keyser/ biß auff Constantinum Magnum [150r] den ersten Christlichen/ und Orientalischen Griechischen Keyser/ Zum andern 42. Keyser von Constantino Magno biß auff Carolum Magnum den ersten Occidentalischen Deutschen Keyser/ Zum dritten 42. von Carolo Magno biß auff jetziger Zeit Regierenden Keyser. Welche Verlauffung der Zahl zum dritten mal Gewisse Kundtschafft und Zeugnuß gibt daß die groß Enderung wiederumb muß vorhanden seyn. Dieweil aber kein andere Enderung mehr seyn kan/ zu einer andern Zeit oder vierden Zeit/ dann eben der Außgang und das End der dritten Zeit deß Evangelii. Derwegen ist gut darauß abzunemmen/ daß etliche vergeblich hoffen auff ein Zunemmung unnd Auffrichtung der Reich der Welt/ oder auch deß Bapstthumbs.

Daß aber die Zahl der Römischen Keyser zu End laufft/ beweist die Analogia und Vergleichung der dreyen Zeiten/ und die Zahl ihrer Succession gegen einander. Dann die erste Zeit Vacui, deß Ledigen/ helt in sich und begreifft die Siebende Zahl Septenarium simpliciter, für sich selbst genommen (wie es dann auch die erste Zeit ist) dreymal/ daß ich sag/ ein mal siebne/ dreymal/ daß seyn 21. von Adam biß auff Loth/ Die Zeit deß Gesatzes aber (wie es die ander Zeit ist) also begreifft sie duplum simpli, oder Duplum Septenarii der ersten Zeit/ das ist/ zweymal sieben oder vierzehen/ in sich auch dreymal/ daß da werden 42. Successiones.

Also die Zeit deß Evangelii/ wie es die dritt Zeit ist/ also begreifft sie Triplum dupli der ander Zeit, daß ist 42 . in sich auch dreymal/ das seyn 126 . Keyser. Wie nuhn die analogia der andern Zeit gegen der ersten sich helt/ also helt sich die dritt gegen den andern / welches dann gnugsam Anzeygung gibt/ daß die Zahl der Römischen Keyser sich erfüll und zu End lauff. Und geschicht nich ohn sonder Geheimnuß/ daß die multiplicatio der Glieder aller dreyen Zeiten mit dem Ternario unnd Septenario geschicht/ welche dann sondere Zahlen seyn/ unnd in Scriptura pro sacris gehalten werden.

del mundo, comprendidos los emperadores del Sacro Imperio, sin duda extraída del manuscrito Speculum et harmonia mundi, Das ist Wellt Spiegel Erster Theil. Puesto que Maximiliano II murió en 1576, la memoria debió ser redactada con anterioridad, lo cual concuerda con el periodo de confección del manuscrito, que se extiende de 1572 a 1579. Sería interesante investigar la posible presencia de esta memoria en los fondos de archivos correspondientes a este emperador. 
Also in der ersten Zeit sag ich/

Einmal siebne dreymal.

[150v] In der andern sag ich/

Zweymal siebne dreymal.

In der dritten/

Sechsmal siebne dreymal.

Da allweg siebne dreymal genendt wird/ in der ersten Zeit einmal/ in der andern zwey$\mathrm{mal} /$ in der dritten sechsmal/ unnd nicht dreymal/ sondern zweymal drey/ Sonst würde kein Analogia der Zahlen der Zeiten seyn/ und würde sich die ander Zeit gegen den dritten nicht halten/ wie sich die erst gegen den andern hält.

Aber also hat die erst Zeit Septenarium, das ist/

Simplum dreymal/

Die ander/

Duplum simpli dreymal.

Ergo, so muß die dritt Zeit haben

Triplum Dupli dreymal/ daß macht sechsmal siebne dreymal/ Sonst wie du es machest/ so gibt es kein rechte Vergleichung.

So wir dann die Successiones und Zahlen der Glieder von Adam biß hieher zusammen addieren unnd summieren/ haben wir 189. Glieder/ und solche Zahl entsteht ex cubo ternarii, welches perfectus Cubus ist, mit sieben multipliciert. Also/ so ich sag/ dreymal drey dreymal/ gibt solches cubum ternarii perfectum, unnd thut 27. solche jetzt mit sieben multipliciert/ thut 189. obermeldte gantze Summa. Dieweil dann solche multiplicatio auß einem Cubo entstanden ist/ da alle drey dimensiones erfunden werden/longitudo, latitudo, \& profunditas, unnd zwar Cubus perfectus ist/ Beweist solches / daß auch die successiones in gemein/ in genere außlauffen/ mit obermeldter Zahl/ von Anfang der Welt biß hieher/ wie sie in specie auch außgelauffen von dem ersten Keiser biß hieher/ in dem die multiplicatio auch geschehen/ mit der vollkommenen Zahl geführt in die sacros numeros. Dann sechse ein vollkommne/ oder perfectus numerus ist/ da ich gesagt/ sechs mal siebene dreymal/ welches machen 126. Keyser. Und das hab ich etwas weitläufftigers außführen wöllen/ damit man sehen kündte/ wie obermeltes Büchlein/ das schrifftlich umbgetragen [152r] wirdt $/ 63$ sein guten Grund unnd Fundament hab/ auß sonderem Geheimnuß der Zahlen [...].

Auß welchem allem zusehen ist/ gleich wie die Zahl der Jahren der Römischen Bäpst zu End laufft/ wie wir oben erwiesen/ in der ersten Frag/64 Also laufft die Zahl der Succession der Keiser auch zu Ende.

\footnotetext{
63 Se trata obviamente de la mencionada memoria de Röslin a Maximiliano II.

64 Cf. Kurtz Bedencken, pp. 128r ss. (Segunda cuestión). Sobre la progresión numérica en el ámbito de las autoridades religiosas (sacerdotes de la Ley y Papas desde Silvestre I) véase Granada, «Helisaeus Roeslin's Chronological Conception and a New Manuscript Source», cit. (nota 24).
} 


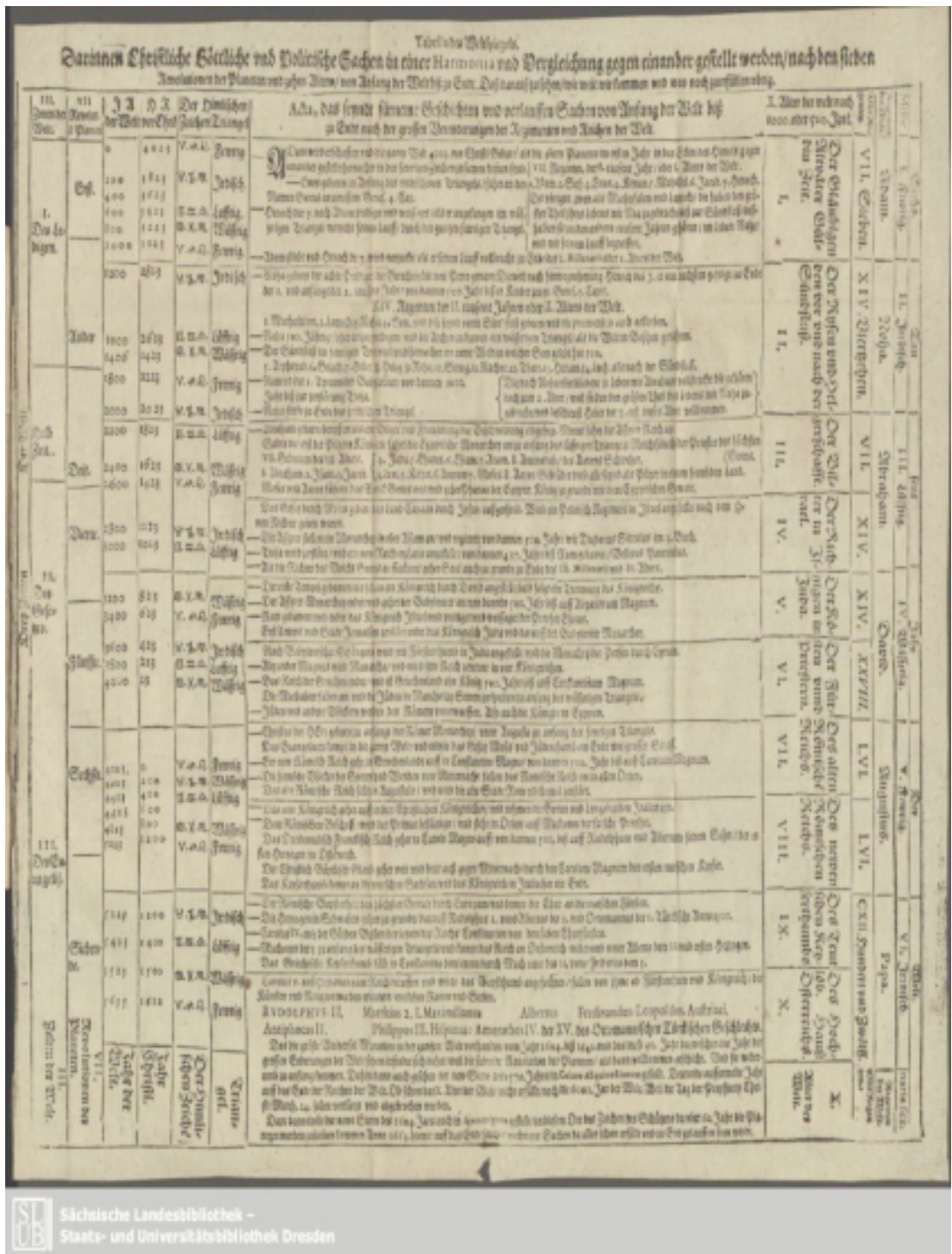

Figura 1. H. Röslin, Tabella des Welt Spiegels, Leipzig, Lorentz Kobern, 1612. Ejemplar en la Biblioteca Digital de la Sächsische Landesbibliothek-Staats und Universitätsbibliothek Dresden.

\author{
Miguel A. Granada \\ Universidad de Barcelona \\ granada@ub.edu
}

